\title{
Association of Oral Diadochokinesis, Physical Function and Swallowing Function in Community-Dwelling Elderly People
}

\author{
Kumiko Sakaguchi ${ }^{*}$, Shuichi Hara ${ }^{2}$ \\ ${ }^{1}$ Department of Department of Speech, Language and Hearing Therapy, Faculty of Health Sciences, Mejiro University, Saitama, \\ Japan \\ ${ }^{2}$ School of Health Science, Kyusyu University of Health and Welfare, Miyazaki, Japan \\ Email: ^kmksakaguchi@gmail.com
}

How to cite this paper: Sakaguchi, K. and Hara, S. (2022) Association of Oral Diadochokinesis, Physical Function and Swallowing Function in Community-Dwelling Elderly People. Advances in Aging Research, 11, 16-25.

https://doi.org/10.4236/aar.2022.111002

Received: December 8, 2021

Accepted: January 24, 2022

Published: January 27, 2022

Copyright $\odot 2022$ by author(s) and Scientific Research Publishing Inc. This work is licensed under the Creative Commons Attribution International License (CC BY 4.0).

http://creativecommons.org/licenses/by/4.0/

\begin{abstract}
Objective: Oral diadochokinesis (ODK) has been shown to be associated with oral frailty. In this study, we investigate the relationship between physical function, swallowing function, nutritional evaluation, and each syllable of ODK. Methods: The subjects are 26 elderly people living in an area where they can walk. ODK, tongue pressure, modified water swallowing test, EAT-10, grip strength, MNA-SF, skeletal muscle index, height, weight, and BMI were evaluated. For statistical analysis based on ODK values, the subjects were divided into two groups on the basis of the number of times the syllables $/ \mathrm{pa} /$, $/ \mathrm{ta} /$, and $/ \mathrm{ka} /$ were repeated: 1 ) The first group with $>6$ repetitions exceeded six; 2) the second group with $\leq 5$ repetitions. Both groups were compared using the Mann-Whitney U test (Model 1). In addition, the syllables /pa/, /ta/, and $/ \mathrm{ka} /$ were also divided among the groups and a comparison was performed (Model 2). Results: In Model 1, the tongue pressure value was significantly higher in the good group $(\mathrm{p}<0.01)$. In Model 2 , the good group showed significantly higher values for the syllables $/ \mathrm{pa} /(\mathrm{p}<0.01)$ and $/ \mathrm{ta} /(\mathrm{p}$ $<0.05)$. There was no significant difference in the values for the syllable $/ \mathrm{ka} /$. Conclusion: In community-dwelling elderly people, tongue pressure was positively associated with ODK values for the syllables /pa/ and /ta/, suggesting that tongue pressure may be associated with strength of the lip and tongue tip muscles. Furthermore, it was suggested that the ODK values may even be lower than normal values in the elderly who maintain skeletal muscle mass and thus have adequate tongue pressure; therefore, these indicators may be used as a guideline to assess oral frailty.
\end{abstract}

\section{Keywords}

Oral Frailty, Oral Diadochokinesis, Community-Dwelling Elderly, 
Swallowing Function, Physical Function

\section{Introduction}

The elderly are prone to suffering from dysphagia due to presbyphagia. They are prone to falling into frailty and sarcopenia compared to the young. Frailty is believed to progress through stages: a social/psychological frailty phase as the 1st stage, then a nutritional frailty phase/oral frailty as the 2nd stage, a physical frailty phase as the 3rd stage, and a severe frailty phase as the 4th stage [1]. Furthermore, although the 1st stage - 3rd stage frailty phases are reversible, the 3rd stage to the 4 th stage are not. In other words, nutritional frailty/oral frailty is understood as a precursor stage for physical frailty. It is thought that if discovery and intervention were possible before falling into physical frailty, not only would it be possible to prevent the progress of frailty, but even to return to a healthy state.

The symptoms of oral frailty include choking on water, reduced occlusal force, etc., but among these, reduced articulation is characteristic. According to the paper by Watanabe et al., the risk of oral frailty is correlated with lower occlusal force and masseter thickness, and oral diadochokinesis (ODK) value [2]. In addition, the Kashiwa Study also concluded that ODK was correlated with oral frailty [3]. Multiple oral frailty-related studies are being performed on community-dwelling elderly persons [4] [5] [6]. However, there are few studies investigating the relationship between ODK and physical function, articulation function, swallowing function, and nutritional state. It is thought that, by identifying ODK-related evaluation items, these may become clues to the early discovery of oral frailty. It is conceivable that performing a proper intervention at an early stage could retroactively restore a healthy state. It would thereby be possible to avoid unnecessary hospitalization of the elderly, and an effect of suppressing medical costs can be expected. Moreover, the elderly themselves would have fewer health-related issues, suggesting the possibility of improved Quality of life as well. In this study, we have performed an investigation of ambulatory community-dwelling elderly persons, for the purpose of elucidating the correlation of ODK with physical function, swallowing function, and nutritional status.

\section{Methods}

\subsection{Subjects}

The subjects were 26 community-dwelling elderly persons who were able to walk independently (Males/Females $=3: 23$, Mean age $85.7 \pm 7.2$ years). The subjects had no history of sequelae such as paralysis. The evaluation items were left/right grip strength, the Modified Water Swallowing Test (MWST), EAT-10, tongue pressure, ODK, MNA-SF, skeletal muscle index (SMI), height, weight, and BMI. Furthermore, in order to verify the difference depending on the frequency of daily utterances, we investigated whether or not they lived with their families. 


\subsection{Grip Strength}

Grip strength was measured using a Smedley hand dynamometer. The measurements were performed standing. The dynamometer was held so that the indicator needle faced outward, and then the grip width was adjusted so that the 2nd knuckle of the index finger was roughly perpendicular [7]. The measurement was performed two times, and the better value was used.

\subsection{Swallowing Function}

The Modified Water Swallowing Test [8] involved injecting 3cc of water into the oral floor using a syringe, which was then swallowed upon instruction. The evaluation was performed with 5 performance descriptors: 1) Unable to swallow, with choking and/or breathing changes; 2) Able to swallow, but with breathing changes (suspected subclinical aspiration); 3) Able to swallow, but with choking and/or wet hoarseness; 4) Able to swallow successfully, with good breathing, no choking; 5) Capable of 2 repeat swallows within 30 seconds in addition to (4).

The EAT-10 [9] question items are shown in Table 1. They are 10 in total, with each question evaluated in 5 stages. A total score of 3 points or higher is judged as abnormal. The questions are each asked according to the question items. Tongue pressure was measured using a tongue pressure measurement device (JMS, Co., Inc.) [10] [11]. The probe was placed on the dorsum of the tongue, and then the subject was instructed to press their tongue against their hard palate. Prior to performing the measurement, the procedure was checked for measurement accuracy. Then, the measurement was performed three times, and the highest value was used.

\subsection{Articulation Function}

ODK was measured by successively pronouncing the monosyllables $/ \mathrm{pa} /, / \mathrm{ta} /$,

Table 1. EAT10 question items.

\begin{tabular}{lc}
\hline \multicolumn{1}{c}{ Symptom } & Score \\
\hline My swallowing problem has caused me to lose weight. & 01234 \\
My swallowing problem interferes with my ability to go out for meals. & 01234 \\
Swallowing liquids takes extra effort. & 01234 \\
Swallowing solids takes extra effort. & 01234 \\
Swallowing pills takes extra effort. & 01234 \\
Swallowing is painful. & 01234 \\
The pleasure of eating is affected by my swallowing. & 01234 \\
When I swallow food sticks in my throat. & 01234 \\
I cough when I eat. & 01234 \\
Swallowing is stressful. & 01234 \\
Total score & 140 \\
\hline
\end{tabular}


and $/ \mathrm{ka} /$ for 5 seconds, respectively, and the number of pronunciations per second was calculated. The measurement used the ODK measurement app "Diadocho" [12].

\subsection{Nutritional Status}

The Mini-Nutritional Assessment Short Form (MNA-SF) [13] [14] [15] questionnaire was administered to evaluate subjective and objective nutritional status. From the 6 evaluation items (food intake, weight loss, mobility, acute disease, psychiatric disorder, and body mass index [BMI]), the nutritional status was evaluated using a 14-point scale as follows: 12 to 14 points, good nutritional status; 8 to 11 points, low risk of nutritional status (at risk); and 0 to 7 points, low nutritional status.

\subsection{Skeletal Muscle Index and Height/Weight}

The skeletal muscle mass was measured by bioelectrical impedance analysis. The measurements used the Inbody270 (InBody Japan). The electrode method of the Inbody270 is the 8-point contact-type electrode method. The impedance of the right arm, left arm, torso, right leg, and left leg was measured using two frequencies: $20 \mathrm{kHz}$ and $100 \mathrm{kHz}$. During measurement, the soles of the feet and palm of the hands were wiped with an associated electrolytic tissue, and measurement was performed after having raised their conductivity. The measured skeletal muscle mass was divided by the square of the height (m), and the skeletal muscle mass index (SMI) was calculated.

As for the height, weight and BMI, user-recorded values were used.

\subsection{Statistical Analysis}

Statistical analysis used SPSS Ver.25, and the iterations of $/ \mathrm{pa} /, / \mathrm{ta} /, / \mathrm{ka} /$ were each grouped into 6-times-or-more group (Higher group) and 5-times-or-less group (Lower group), and the Mann-Whitney U-test was performed (Model 1). In addition, for the respective syllables of $/ \mathrm{pa} /, / \mathrm{ta} /, / \mathrm{ka} /, 6$-times-or-more was treated as the Higher group (ex. /pa/: Higher group (pa)), while 5-times-or-less were treated as the Lower group (ex. /pa/: Lower group (pa)), and the MannWhitney U-test was performed (Model 2). Furthermore, for Model 3, we compared the groups according to whether or not they lived with their families. In both analyses, the significance level was $\mathrm{p}<0.05$.

\section{Ethical Considerations}

This study was performed with the approval of the "Mejiro University: Ethics Review Board for Research on Humans and Animals".

\section{Results}

Table 2 shows the information for all subjects. The median BMI for all subjects was $22.6(20.9-24.3) \mathrm{kg} / \mathrm{m}^{2}$, while the median SMI was $7.6(7.0-8.3) \mathrm{kg} / \mathrm{m}^{2}$. The 
Table 2. Baseline characteristics $(n=26)$.

\begin{tabular}{cc}
\hline & Median (Interquartile range) \\
\hline Height $(\mathrm{cm})$ & $148.2(143.7-150.7)$ \\
Weight $(\mathrm{kg})$ & $48.3(44.7-54.4)$ \\
BMI $\left(\mathrm{kg} / \mathrm{m}^{2}\right)$ & $22.6(20.9-24.3)$ \\
SMI $\left(\mathrm{kg} / \mathrm{m}^{2}\right)$ & $7.6(7.0-8.3)$ \\
Left grip strength $(\mathrm{kg})$ & $16.6(15.3-22.4)$ \\
Right grip strength $(\mathrm{kg})$ & $17.6(13.6-20.9)$ \\
EAT-10 score & $0.0(0.0-2.0)$ \\
MWST score & $5.0(4.0-5.0)$ \\
Tongue pressure $(\mathrm{kPa})$ & $29.6(21.3-35.3)$ \\
$/ \mathrm{pa} /($ number of times/sec) & $4.9(3.8-5.9)$ \\
$/ \mathrm{ta} /($ number of times/sec) & $5.1(3.8-6.1)$ \\
$/ \mathrm{ka} /($ number of times/sec) & $4.8(3.4-5.6)$ \\
MNA-SF score & $13.0(12.0-14.0)$ \\
\hline
\end{tabular}

median grip strength was Left: $16.6(15.3$ - 22.4) kg, Right: $17.6(13.6$ - 20.9) kg. The tongue pressure was $29.6(21.3-35.3) \mathrm{kPa}$. The MWST was profile 4 or $5 \mathrm{in}$ all subjects. The median EAT-10 was $0(0.0-2.0)$, while the respective ODKs were /pa/: $4.9(3.8$ - 5.9) times, /ta/: $5.1(3.8$ - 6.1) times, /ka/: $4.8(3.4-5.6)$ times.

Table 3 shows results of the Mann-Whitney U-test, grouped according to the overall ODK results. The median tongue pressure was 36.1 (30.6 - 40.7) $\mathrm{kPa}$ for the Higher group, and $24.7(20.1-31.3) \mathrm{kPa}$ for the Lower group. The score of the Higher group was significantly greater $(\mathrm{p}<0.01)$.

Table 4 shows the results of Model 2. In /pa/, the median tongue pressure was 36.1 (32.4 - 40.3) $\mathrm{kPa}$ for the Higher group (pa), and $24.7(20.2$ - 31.6) $\mathrm{kPa}$ for the Lower group (pa). The Higher group's score was significantly greater $(\mathrm{p}<$ $0.01)$. In the / ta/ comparison, the median tongue pressure was 33.8 (29.7 - 41.2) $\mathrm{kPa}$ for the Higher group (ta), and $26.3(20.3$ - 31.7) $\mathrm{kPa}$ for the Lower group (ta). The score of the Higher group (ta) was significantly greater $(\mathrm{p}<0.05)$. There were no items for which significant differences were observed in the comparison of $/ \mathrm{ka} /$.

Table 5 shows the results of Model 3. No significant difference was found in the comparison based on whether or not the family lived together.

\section{Discussion}

This study investigated the correlation of ODK with physical function, swallowing function, and nutritional status in ambulatory community-dwelling elderly persons. We treated the group where the ODK value, the judgement criterion for oral frailty, was 6 times or more per second as the Higher group, and the 5 times 
Table 3. Results of model 1.

\begin{tabular}{ccc}
\hline & \multicolumn{2}{c}{ Median (Interquartile range) } \\
\cline { 2 - 3 } & Higher group $(\mathrm{N}=18)$ & Lower group $(\mathrm{N}=8)$ \\
\hline Height $(\mathrm{cm})$ & $148.2(143.7-150.7)$ & $147.9(142.5-150.7)$ \\
Weight $(\mathrm{kg})$ & $48.3(44.7-54.4)$ & $46.2(41.6-53.8)$ \\
BMI $\left(\mathrm{kg} / \mathrm{m}^{2}\right)$ & $22.9(22.0-26.6)$ & $22.5(20.9-24.1)$ \\
SMI $\left(\mathrm{kg} / \mathrm{m}^{2}\right)$ & $7.7(7.4-8.7)$ & $7.4(6.9-8.2)$ \\
Left grip strength $(\mathrm{kg})$ & $18.8(12.8-22.5)$ & $16.6(15.7-21.5)$ \\
Right grip strength $(\mathrm{kg})$ & $19.4(13.7-23.9)$ & $17.0(13.3-20.3)$ \\
EAT-10 score & $0.0(0.0-1.0)$ & $0.0(0.0-2.3)$ \\
MWST score & $4.0(4.0-5.0)$ & $5.0(4.0-5.0)$ \\
Tongue pressure $(\mathrm{kPa})$ & $36.1(30.6-40.7)^{\star *}$ & $24.7(20.1-31.3)^{* *}$ \\
MNA-SF score & $13.5(13.0-14.0)$ & $13.0(11.8-14.0)$ \\
\hline$* * 00.01 . \quad$ &
\end{tabular}

Table 4. Results of model 2.

\begin{tabular}{|c|c|c|c|c|c|c|}
\hline & \multicolumn{6}{|c|}{ Median (Interquartile range) } \\
\hline & \multicolumn{2}{|c|}{$/ \mathrm{pa} /$} & \multicolumn{2}{|c|}{$/ \mathrm{ta} /$} & \multicolumn{2}{|c|}{$/ \mathrm{ka} /$} \\
\hline & $\begin{array}{l}\text { Higher group } \\
\qquad(\mathrm{N}=20)\end{array}$ & $\begin{array}{l}\text { Lower group } \\
\qquad(\mathrm{N}=6)\end{array}$ & $\begin{array}{l}\text { Higher group } \\
\qquad(\mathrm{N}=19)\end{array}$ & $\begin{array}{l}\text { Lower group } \\
\qquad(\mathrm{N}=7)\end{array}$ & $\begin{array}{l}\text { Higher group } \\
\qquad(\mathrm{N}=23)\end{array}$ & $\begin{array}{l}\text { Lower group } \\
\qquad(\mathrm{N}=3)\end{array}$ \\
\hline Height $(\mathrm{cm})$ & $\begin{array}{c}148.2 \\
(143.7-150.7)\end{array}$ & $\begin{array}{c}148.2 \\
(142.7-151.6)\end{array}$ & $\begin{array}{c}149.2 \\
(147.5-152.1)\end{array}$ & $\begin{array}{c}147.7 \\
(142.6-150.2)\end{array}$ & $\begin{array}{c}149.1 \\
(147.5-149.2)\end{array}$ & $\begin{array}{c}148.1 \\
(143.1-152.1)\end{array}$ \\
\hline Weight (kg) & $48.3(44.7-54.4)$ & $47.2(42.0-54.1)$ & $53.9(48.5-62.3)$ & $46.1(41.7-53.6)$ & $48.5(45.3-63.6)$ & $48.1(42.9-54.2)$ \\
\hline BMI $\left(\mathrm{kg} / \mathrm{m}^{2}\right)$ & $22.9(21.6-25.8)$ & $22.5(20.9-24.2)$ & $23.4(22.1-27.2)$ & $22.1(20.9-24.0)$ & $22.3(20.3-28.6)$ & $22.8(20.9-24.3)$ \\
\hline $\mathrm{SMI}\left(\mathrm{kg} / \mathrm{m}^{2}\right)$ & $8.1(7.3-8.9)$ & $7.4(6.9-8.1)$ & $7.9(7.4-8.8)$ & $7.5(6.9-8.2)$ & $8.3(7.0-8.8)$ & $7.5(7.0-8.2)$ \\
\hline Left grip strength $(\mathrm{kg})$ & $18.8(13.8-23.5)$ & $16.6(15.6-21.9)$ & $21.9(14.4-22.6)$ & $16.5(15.6-20.5)$ & $21.9(14.4-22.6)$ & $16.5(15.6-22.3)$ \\
\hline Right grip strength (kg) & $20.2(13.2-25.3)$ & $17.0(13.7-20.5)$ & $20.7(14.1-24.4)$ & $17.0(12.5-20.2)$ & $22.3(13.6-24.4)$ & $17.0(13.6-20.6)$ \\
\hline EAT-10 score & $0.0(0.0-1.3)$ & $0.0(0.0-2.0)$ & $0.0(0.0-1.0)$ & $0.0(0.0-2.0)$ & $0.0(0.0-1.0)$ & $0.0(0.0-2.0)$ \\
\hline MWST score & $4.0(4.0-5.0)$ & $5.0(4.0-5.0)$ & $4.0(4.0-5.0)$ & $5.0(4.0-5.0)$ & $5.0(4.0-5.0)$ & $5.0(4.0-5.0)$ \\
\hline Tongue pressure $(\mathrm{kPa})$ & $36.1(32.4-40.3)^{* \star}$ & $24.7(20.2-31.6)^{\star \star}$ & $33.8(29.7-41.2)^{\star}$ & $26.3(20.3-31.7)^{*}$ & $33.3(29.7-33.8)$ & $27.3(20.3-38.1)$ \\
\hline MNA-SF score & $13.0(12.8-14.0)$ & $13.0(12.0-14.0)$ & $13.0(13.0-14.0)$ & $13.0(12.0-14.0)$ & $13.0(13.0-14.0)$ & $13.0(12.0-14.0)$ \\
\hline
\end{tabular}

${ }^{\star *} \mathrm{p}<0.01 ;{ }^{\star} \mathrm{p}<0.05$.

Table 5. Results of model 3.

\begin{tabular}{lcc}
\hline & \multicolumn{2}{c}{ Median (Interquartile range) } \\
\cline { 2 - 3 } & Live with family $(\mathrm{N}=18)$ & $\begin{array}{c}\text { Living alone or } \\
\text { Nursing home }(\mathrm{N}=7)\end{array}$ \\
\hline Height $(\mathrm{cm})$ & $149.2(143.9-152.1)$ & $147.7(143.1-149.1)$ \\
Weight $(\mathrm{kg})$ & $46.2(41.7-55.0)$ & $53.1(45.9-53.6)$ \\
\hline
\end{tabular}




\section{Continued}

\begin{tabular}{lcc}
\hline BMI $\left(\mathrm{kg} / \mathrm{m}^{2}\right)$ & $22.1(20.9-24.0)$ & $23.0(20.9-26.5)$ \\
SMI $\left(\mathrm{kg} / \mathrm{m}^{2}\right)$ & $7.4(6.9-7.9)$ & $8.3(7.2-8.8)$ \\
Left grip strength $(\mathrm{kg})$ & $15.9(12.2-22.3)$ & $20.1(16.5-24.3)$ \\
Right grip strength $(\mathrm{kg})$ & $18.1(12.5-20.6)$ & $17.0(16.0-24.4)$ \\
EAT-10 score & $0.0(0.0-2.0)$ & $0.0(0.0-1.0)$ \\
MWST score & $4.0(4.0-5.0)$ & $5.0(4.0-5.0)$ \\
Tongue pressure $(\mathrm{kPa})$ & $26.3(20.1-34.4)$ & $29.7(27.3-38.1)$ \\
$/ \mathrm{pa} /$ (number of times/sec) & $5.2(3.4-6.2)$ & $4.6(4.2-5.8)$ \\
$/ \mathrm{ta} /($ number of times/sec) & $5.0(3.6-6.2)$ & $5.4(3.8-5.8)$ \\
$/ \mathrm{ka} /$ (number of times/sec) & $5.0(3.4-5.6)$ & $4.6(3.4-5.4)$ \\
$\mathrm{MNA}$-SF score & $13.0(12.0-14.0)$ & $14.0(13.0-14.0)$ \\
\hline
\end{tabular}

or less group as the Lower group. Among /pa//ta//ka/, 6 times or more for any of these was treated as the Higher group, and the tongue pressure of the Higher group was significantly higher than that of the Lower group. Even in the case of grouping subjects according to /pa/ iterations, the Higher group (pa) had significantly higher tongue pressure values compared to the Lower group (pa). Similarly, in /ta/, the Higher group (ta) had significantly higher tongue pressure values compared to the Lower group (ta). No significant difference was seen in any comparison for $/ \mathrm{ka} /$.

In this study, a correlation was seen between tongue pressure and the /pa/ and /ta/ of ODK. "Tongue pressure" measures the muscular strength of the tongue by placing the measurement balloon at the dorsum of the tongue, and then pressing the back of the tongue against the hard palate. According to the International Phonetic Alphabet (IPA) [16], the syllable /pa/ is a bilabial consonant and $/ \mathrm{ta} /$ is an alveolar consonant. /ta/ is pronounced by forming a closure between the anterior tongue and the alveolar ridge and is released with an exhalation. Because of the articulation point/articulation method of /ta/, it is thought possible that the articulation of /ta/ requires anterior tongue mobility and strength. In this study, the correlation seen with the tongue pressure measuring the strength of the dorsum of the tongue, and specifically the anterior tongue, is thought to affect the articulation characteristics of /ta/. In contrast, the correlation with /pa/ was a result suggestive of a correlation of tongue pressure with labial mobility and muscular strength. With regard to the correlation between lip closure and tongue pressure, Sakai et al. [17] have stated that a correlation is seen between lip closure and tongue strength in elderly hospitalized patients, and is useful as an indicator of sarcopenia-associated dysphagia. Because lip closure was not measured in this study, it is difficult to say that the results would be completely the same. Still, the results supported the results of the study by Sakai et al.

In healthy elderly persons, ODK, grip strength, and SMI decrease in proportion to age [18] [19] [20]. Furthermore, ODK, grip strength, and SMI exhibit a 
correlation with oral frailty and sarcopenia [21]. Similarly, in this study, although no significant difference was seen in SMI and left/right grip strength, the comparisons of both /pa/ and /ta/ tended to be low in the Poor group. The results were similar to previous research, and no significant difference was seen. In this study, because the number of subjects was small, we believe that analysis with increased number of subjects will be needed in the future.

The concept of "oral frailty" has garnered attention in recent years, and research on the prevention of oral frailty is proliferating. Oral frailty is thought to be a gateway for systemic frailty. It is thought that early diagnosis/early intervention at the oral frailty stage can prevent systemic frailty. Moreover, it is frequently the case that the reduced functionality is reversible in the oral frailty stage through proper intervention, and it is possible to return to a healthy state

[22]. Tongue pressure is reported to be not only an indicator of oral frailty, but also correlated with meal type in persons with dysphagia. However, there is a limited number of hospitals and facilities that possess tongue pressure measurement devices. In this regard, because ODK evaluation can be performed even without equipment, it is possibly suitable as a screening test.

The limitations of this study were the insufficient number of subjects and the gender imbalance. In the future, we would like to perform a high-precision analysis that increases the number of subjects and includes sex difference. In addition, it will be necessary to add evaluation methods other than MWST as evaluations of swallowing function. In terms of the subject characteristics, there was unlikely to be greater than moderate dysphagia, and evaluation with MWST may have been insufficient. Because subjects without dysphagia were included, the specialist examinations VF and VE were problematic from an ethical perspective; however, we would like to perform examinations with the addition of evaluations with low-invasiveness such as a water swallowing test. Moreover, because a correlation was exhibited between ODK /pa/ and tongue pressure, we believe that additional analysis of labial closure will be necessary. Furthermore, it is necessary to investigate the relationship with brain function. At the stage, the brain function of ODK has not been elucidated, but previous studies have reported areas of the brain involved in improving speech fluency and speech motility in PD patients [23]. It is also reported that the lower part of the precentral gyrus is involved in the programming of articulation movements [24]. Consequently, it is speculated that there are various parts of the brain involved in speech movements related to ODK, and further studies are needed.

\section{Conclusion}

In ambulatory community-dwelling elderly persons, it is thought that there is a correlation between tongue pressure and / $\mathrm{pa} / \mathrm{and} / \mathrm{ta} /$ of ODK, as well as a correlation between tongue pressure and the muscular strength of the lips and lingual apex. Furthermore, even in elderly persons maintaining skeletal muscle mass and tongue pressure, it was possible for the ODK value to drop below 
normal, implying a possible criterion for oral frailty.

\section{Acknowledgements}

We would like to thank all our subjects. We are grateful to all parties at "Roken Atago (Miyazaki, Japan)".

\section{Conflicts of Interest}

The authors declare no conflicts of interest.

\section{References}

[1] Fried, L.P., Tangen, C.M., Walston, J., Newman, A.B., Hirsch, C., Gottdiener, J., Seeman, T., Tracy, R., Kop, W.J., Burke, G. and McBurnie, M.A. (2001) Frailty in Older Adults: Evidence for a Phenotype. The Journals of Gerontology: Series A, 56, M146-M156. https://doi.org/10.1093/gerona/56.3.M146

[2] Watanabe, Y., Hirano H., Arai, H., Morishita S., Ohara, Y., Edahiro, A., Murakami, M., Shimada, H., Kikutani, T. and Suzuki, T. (2017) Relationship between Frailty and Oral Function in Community-Dwelling Elderly Adults. Journals of the American Geriatrics Society, 65, 66-76. https://doi.org/10.1111/jgs.14355

[3] Ishii, S., Tanaka, T., Shibasaki, K., Ouchi, Y., Kikutani, T., Higashiguchi, T., Obuchi, S.P., Ishikawa-Takata, K., Hirano, H., Kawai, H., Tsuji, T. and Iijima, K. (2014) Development of a Simple Screening Test for Sarcopenia in Older Adults. Geriatrics \& Gerontology International, 14, 93-101. https://doi.org/10.1111/ggi.12197

[4] Tanaka, T., Takahashi, K., Hirano, H., Kikutani, T., Watanabe, Y., Ohara, Y., Furuya, H., Tetsuo, T., Akishita, M. and Iijima, K. (2018) Oral Frailty as a Risk Factor for Physical Frailty and Mortality in Community-Dwelling Elderly. The Journals of Gerontology: Series A, 73, 1661-1667. https://doi.org/10.1093/gerona/glx225

[5] Nishida, T., Yamabe, K. and Honda, S. (2020) Dysphagia Is Associated with oral, Physical, Cognitive and Psychological Frailty in Japanese Community-Dwelling Elderly Persons. Gerodontology, 37,185-190. https://doi.org/10.1111/ger.12455

[6] Hironaka, S., Kugimiya, Y., Watanabe, Y., Motokawa, K., Hiranobe, H., Kawai, H., Kera, T., Kojima, M., Fujiwarai, Y., Ihara, K., Kim, H., Obuchi, S. and Kakinoki, Y. (2020) Association between Oral, Social, and Physical Frailty in Community-Dwelling Older Adults. Archives of Gerontology and Geriatrics, 89, Article ID: 104105. https://doi.org/10.1016/j.archger.2020.104105

[7] Ministry of Education, Culture, Sports, Science and Technology-Japan (1999) New Physical Fitness Test Implementation Guidelines. (In Japanese) https://www.mext.go.jp/component/a_menu/sports/detail/__icsFiles/afieldfile/2010 /07/30/1295079_04.pdf

[8] Tohara, H., Saitoh, E., Mays K.A., Kuhlemeier, K. and Palmer, J.B. (2003) Three Tests for Predicting Aspiration without Video Fluorography. Dysphagia, 18, 126-134. https://doi.org/10.1007/s00455-002-0095-y

[9] Wakabayashi, H. and Kayashita, J. (2014) Translation, Reliability, and Validity of the Japanese Version of the 10-Item Eating Assessment Tool (EAT-10) for the Screening of Dysphagia. The Journal of Japanese Society for Parenteral and Enteral Nutrition, 29, 871-876. (In Japanese) https://doi.org/10.11244/jjspen.29.871

[10] Yoshikawa, M., Yoshida, M., Tsuga, K., Akagawa Y. and Groher, M.E. (2011) Comparison of Three Types of Tongue Pressure Measurement Devices. Dysphagia, 26, 232-237. https://doi.org/10.1007/s00455-010-9291-3 
[11] Tsuga, K., Maruyama, M., Yoshikawa, M., Yoshida, M. and Akagawa, Y. (2011) Manometric Evaluation of Oral Function with a Hand-Held Balloon Probe. Journal of Oral Rehabilitation, 38, 680-685.

https://doi.org/10.1111/j.1365-2842.2011.02202.x

[12] Hara, S. and Miura, H. (2018) Development of an Application for Evaluating Oral Diadochokinesis for Community Oral Health Activities Confirmation of Reliability and Validity. Japanese Journal of Gerodontology, 33, 344-349. (In Japanese)

[13] Rubenstein L.Z., Harker J., Salva A., Guigoz Y. and Vellas B. (2001) Screening for Undernutrition in Geriatric Practice: Developing the Short-Form Mini-Nutritional Assessment (MNA-SF). The Journals of Gerontology: Series A, 56, M366-M372. https://doi.org/10.1093/gerona/56.6.M366

[14] Kuzuya M., Kanda S., Koike T., Suzuki Y., Satake S. and Iguchi A. (2005) Evaluation of Mini-Nutritional Assessment for Japanese Frail Elderly. Nutrition, 21, 489-503. https://doi.org/10.1016/j.nut.2004.08.023

[15] Izawa S., Kuzuya M., Okada K., Enoki H., Koike T., Kanda S. and Iguchi A. (2006) The Nutritional Status of Frail Elderly with Care Needs According to the MiniNutritional Assessment. Clinical Nutrition, 25, 962-967.

https://doi.org/10.1016/j.clnu.2006.05.006

[16] International Phonetic Association (2015) Full IPA Chart. https://www.internationalphoneticassociation.org/content/full-ipa-chart\#ipachartdeja

[17] Sakai, K., Nakayama, E., Tohara, H., Takahashi, O., Ohnishi, S., Tsuzuki, H., Hayata, M., Takehisa, T., Takehisa, Y. and Ueda, K. (2019) Diagnostic Accuracy of Lip Force and Tongue Strength for Sarcopenic Dysphagia in Older Inpatients: A CrossSectional Observational Study. Clinical Nutrition, 38, 303-309. https://doi.org/10.1016/j.clnu.2018.01.016

[18] Hara, S., Miura, H. and Yamasaki, K. (2013) Oral Diadochokinesis among Japanese Aged over 55 Years: Analysis of Standard Values. Japanese Journal of Geriatrics, 50, 258-263. (In Japanese) https://doi.org/10.3143/geriatrics.50.258

[19] Kallman, D.A., Plato, C.C. and Tobin, J.D. (1990) The Role of Muscle Loss in the Age-Related Decline of Grip Strength: Cross-Sectional and Longitudinal Perspectives. Journal of Gerontology, 45, M82-M88.

https://doi.org/10.1093/geronj/45.3.M82

[20] Shimokata, H., Ando, F., Yuki, A. and Otsuka, R. (2014) Age-Related Changes in Skeletal Muscle Mass among Community-Dwelling Japanese: A 12-Year Longitudinal Study. Geriatrics \& Gerontology International, 14, 85-92. https://doi.org/10.1111/ggi.12219

[21] Kobuchi, R., Okuno, K., Kusunoki, T., Inoue, T. and Takahashi, K. (2020) The Relationship between Sarcopenia and Oral Sarcopenia in Elderly People. Journal of Oral Rehabilitation, 47, 636-642. https://doi.org/10.1111/joor.12948

[22] Iijima, K. (2015) Upstream Preventive Strategy for Age-Related Sarcopenia in the Elderly: Why Do the Elderly Fall into Inadequate Nutrition? Annals of Japan Prosthodontic Society, 7, 92-101. (In Japanese) https://doi.org/10.2186/ajps.7.92

[23] Wang, E.Q., Metman, L.V. and Bakay, R.A.E. (2006) Hemisphere-Specific Effects of Subthalamic Deep Brain Stimulation on Speaking Rate and Articulatory Accuracy of Syllable Repetitions in Parkinson's Disease. Journal of Medical Speech-Language Pathology, 14, 323-334.

[24] Yeske, B., Hou J., Adluru, N., Nair, V.A. and Prabhakaran, V. (2021) Differences in Diffusion Tensor Imaging White Matter Integrity Related to Verbal Fluency between Young and Old Adults. Frontiers in Aging Neuroscience, 13, Article ID: 750621. https://doi.org/10.3389/fnagi.2021.750621 